\title{
Plasmid diversity in Chlamydia
}

\author{
N. S. Thomas, ${ }^{1}$ M. Lusher, ${ }^{2}$ C. C. Storey ${ }^{2}$ and I. N. Clarke ${ }^{1}$ \\ Author for correspondence: I. N. Clarke. Tel: +44 1703 796975. Fax: +44 1703774316. \\ e-mail: inc@soton.ac.uk
}

1 Molecular Microbiology, University of Southampton Medical School

Southampton General Hospital, Southampton SO16 6YD, UK

2 University of Manchester, Department of

Pathological Sciences, Virology Division, Oxford Road, Manchester M13 9PT, UK

\begin{abstract}
Chlamydiae exhibit low interspecies DNA homology and plasmids from different chlamydial species can be readily distinguished by Southern blot analysis and restriction enzyme profiling. In contrast, available plasmid sequence data from within the species Chlamydia trachomatis indicate that plasmids from human isolates are highly conserved. To evaluate the nature and extent of plasmid variation, the complete nucleotide sequences were determined for novel plasmids from three diverse non-human chlamydial isolates: pCpA1 from avian Chlamydia psittaci (N352); pCpnE1 from equine Chlamydia pneumoniae (N16); and pMoPn from C. trachomatis mouse pneumonitis. Comparison of the sequence data did not identify an overall biological function for the plasmid but did reveal considerable sequence conservation ( $>60 \%$ ) and a remarkably consistent genomic arrangement comprising eight major ORFs and four 22 bp tandem repeats. The plasmid sequences were close to 7500 nucleotides in length (pCpA1, 7553 bp; pMoPn, 7502 bp) however the equine $C$. pneumoniae plasmid was smaller (7362 bp) than all other chlamydial plasmids. The reduced size of this plasmid was due to a single large deletion occurring within ORF 1 ; this potentially generates two smaller ORFs. The disruption of ORF 1 is the only significant variation identified amongst the chlamydial plasmids and could prove important for future vector development studies.
\end{abstract}

Keywords: chlamydia, plasmid

\section{INTRODUCTION}

Chlamydia spp. are intracellular pathogens responsible for a wide range of important medical and veterinary diseases. With the addition of Chlamydia pecorum (Fukushi \& Harai, 1992), four species are currently recognized within the genus Chlamydia. Chlamydia trachomatis and Chlamydia pneumoniae are predominately human pathogens, although recently strains of both species infecting other mammals have been described, while Chlamydia psittaci and Chlamydia pecorum are mainly pathogenic to birds and mammals. Chlamydia have an absolute requirement for ATP from the host cell and cannot be grown on synthetic media. Chlamydia have no near eubacterial relatives and are themselves highly diverse, with interspecies genomic DNA homology as low as $10 \%$ (Kingsbury \& Weiss,

Abbreviations: $E B$, elementary body; MoPn, mouse pneumonitis. The EMBL accession numbers for the plasmid sequences reported in this paper are $X 62475, X 82078$ and $X 76707$ for pCpA1, pCpnE1 and pMoPn, respectively
1968). Despite this lack of DNA homology and extensive differences in host range and pathogenicity, all chlamydiae share a number of biological features. Most notable is their unique developmental life-cycle involving two alternating forms; the larger reticulate bodies multiply by binary fission until, at the end of the lifecycle they condense to form the smaller metabolically inert but infectious elementary bodies (EBs; Ward, 1988).

A physical and genetic map of the C. trachomatis chromosome describes a genome of $1045 \mathrm{~kb}$ (Birkelund \& Stephens, 1992). This is one of the smallest prokaryotic genomes and it is likely that there are many genetic factors absent from the chlamydial genome relative to other bacteria (Hatch, 1988). In addition to the genome, extrachromosomal DNA elements have been identified in isolates from all four chlamydial species. Plasmids were initially described in both C. trachomatis and C. psittaci by Lovett et al. (1980). Also, a $22 \mathrm{~nm}$ diameter icosahedral bacteriophage, later called chlamydiophage, was first observed by thin section electronmicroscopy specifically from duck isolates of 
C. psittaci (Richmond et al., 1982). Following these early reports, there have been many studies describing the molecular characterization of chlamydial plasmids and the chlamydiophage, which have been reviewed by Lusher et al. (1991). The plasmid and the phage are unrelated and there is no sequence homology between them (Storey et al., 1989).

Several complete plasmid sequences have been published for human C. trachomatis isolates, from serovars B (Sriprakash \& MacAvoy, 1987), L2 (Comanducci et al., 1988; Black et al., 1989), L1 (Hatt et al., 1988; Thomas \& Clarke, 1992) and D (Comanducci et al., 1990). This work showed that all plasmids from human C. trachomatis isolates are highly conserved (less than 1\% nucleotide sequence variation), almost uniform in size at 7500 nucleotides and encode eight significant ORFs greater than 100 amino acids. Database searches have indicated putative functions for five of the eight ORFs, in addition ORF 5 encodes a protein of $28 \mathrm{kDa}$ (pgp3) which has been expressed in Escherichia coli (Comanducci et al., 1993). This protein may be a marker for current chlamydial infection and can be clearly identified by staining inclusions in chlamydia-infected cells (Comanducci et al., 1994). However, the possible role of pgp3 in the chlamydial life-cycle and the overall biological function of the plasmid remain unknown.

Characterization of plasmid functions and of chlamydial genes in general has been greatly impeded by the lack of a genetic system for Chlamydia. Electron microscopical examination of plasmid DNA (Tam et al., 1992) has shown that the plasmid origin of replication is located close to the $22 \mathrm{bp}$ tandem repeats and that replication is unidirectional. Since the plasmid of C. trachomatis may be under positive selection and is found in most isolates of this species, it appears the most promising candidate for vector development. The cryptic plasmid has been used for the construction of a preliminary chlamydial 'vector' using a promoterless chloramphenicol acetyltransferase cassette inserted into ORF 1 (Tam et al., 1994). However, transformation was inefficient and transformants were unstable, surviving a maximum of only four passages in cell culture.

The principal difficulty of using the cryptic plasmid as a cloning vehicle is in identifying non-essential parts of the sequence that may be replaced or modified during vector construction. It is clear that the plasmid is not essential for chlamydial growth as one strain of C. trachomatis (Peterson et al., 1990) and possibly some clinical isolates have been described that are plasmid-free (An et al., 1992). In addition, several C. psittaci (Lusher et al., 1991) and all human C. pneumoniae (Campbell et al., 1987; Lusher et al., 1989) isolates so far analysed do not have the cryptic $7.5 \mathrm{~kb}$ plasmid. The purpose of this work was to define the extent of natural variation between potentially diverse plasmids from three chlamydial species and thereby identify non-essential regions of the plasmid. We have chosen plasmids from the avian (duck) strain N352 of C. psittaci, the equine isolate N16 which is the only plasmid-carrying strain of C. pneu- moniae (Storey et al., 1993; Black et al., 1994) and the plasmid from the mouse pneumonitis $(\mathrm{MoPn})$ strain of C. trachomatis (Nigg, 1942). In Southern blotting experiments this latter plasmid has been reported not to share homology with the other C. trachomatis plasmids and to be several hundred bases larger (Palmer \& Falkow, 1986). The complete nucleotide sequences of these three plasmids were determined and compared with the sequence of the serovar L1 plasmid, which is representative of the human C. trachomatis plasmids.

\section{METHODS}

Growth of chlamydiae and purification of EBs. The chlamydial strains employed in this study and the designations of the native plasmids are shown in Table 1 . Chlamydiae were propagated in BGMK cell monolayers in plastic culture flasks (Flow Laboratories) in the presence of cyclohexamide. The host cells were grown in Dulbecco's modified essential medium (Flow Laboratories), supplemented with $10 \%(\mathrm{v} / \mathrm{v})$ foetal calf serum, $1 \%$ non-essential amino acids and $20 \mu \mathrm{g}$ gentamicin $\mathrm{ml}^{-1}$ (Sigma). EBs were prepared by centrifugation through $32 \%(\mathrm{v} / \mathrm{v})$ Urografin 370 (Schering) or through $25 \%(\mathrm{w} / \mathrm{v})$ Triosil 440 (Nycomed).

Preparation and cloning of plasmid DNA. Plasmid DNA was prepared from purified C. psittaci and C. pneumoniae EBs by the method of Birnboim \& Doly (1979), except that the lysozyme treatment was omitted. Plasmid DNA preparations were digested with EcoRI. Four EcoRI restriction fragments of $6.2,0.6,0.4$ and $0.2 \mathrm{~kb}$ were obtained for pCpA1 and five EcoRI restriction fragments of $4 \cdot 2,1.3,1.2,0.4$ and $0.3 \mathrm{~kb}$ were obtained for pCpnE1. These fragments were ligated into pUC vector DNA cleaved with EcoRI and used to transform E. coli JM83. Additionally pCpA1 and pCpnE1 were cloned via their unique BalI restriction sites into SmaI-cleaved pUC9.

Total DNA was extracted and purified from C. trachomatis MoPn EBs by incubation at $37{ }^{\circ} \mathrm{C}$ with $1.4 \%$ (w/v) Sarkosyl (Sigma) and $200 \mathrm{ng}$ Proteinase $\mathrm{K} \mathrm{ml}^{-1}$ followed by sequential extraction with (i) phenol, (ii) $50 \%(\mathrm{v} / \mathrm{v})$ phenol/chloroform and (iii) chloroform. This DNA preparation was digested with EcoRI and ligated into lambda Ziplox EcoRI arms (D'Alessio et al., 1992). The bacteriophage vector was assembled by an in vitro packaging system (Life Technologies) and mixed with $E$. coli strain Y1090 (ZL) in Luria-Bertani broth (LB) containing $0.2 \%(\mathrm{w} / \mathrm{v})$ maltose. The resulting phage library was screened by standard hybridization techniques (Sambrook et al., 1989) using the complete cryptic plasmid from C. trachomatis serovar L1 (pLGV/440) as a probe (Thomas \& Clarke, 1992).

For preparation of sequencing templates, the required recombinants were grown in liquid culture and plasmid DNA isolated by standard alkaline lysis followed by purification with either $\mathrm{CsCl} /$ ethidium bromide gradient centrifugation (Sambrook et al., 1989) or by nucleic acid chromatography system (NACS) from Life Technologies.

Nucleotide sequence determination. Purified recombinant plasmid DNA from pCpA1 was used either directly for sequencing reactions (Hattori \& Sakaki, 1986) or purified insert DNA was subcloned into M13mp18 or M13mp19 (Yanisch-Perron et al., 1985) after partial digestion with restriction enzymes: AluI, BglII, DraI, HindIII, Sau3A or TaqI. Sequence determination of pCpA1 was by the dideoxynucleotide chain-termination method (Sanger et al., 1977), using M13 universal primers or synthetic oligonucleotide 
Table 1. Chlamydial strains and plasmids

\begin{tabular}{|lllll|}
\hline Species & Host & Strain & Plasmid & \multicolumn{1}{c|}{ Reference } \\
\cline { 5 - 5 } C. trachomatis & Human & L1/440/LN & pLGV440 & Schachter \& Meyer (1969) \\
C. trachomatis" & Murine & MoPn & pMoPn & Nigg (1942) \\
C. psittaci & Avian & N352 & pCpA1 & Richmond et al. (1982) \\
C. pneumoniae & Equine & N16 & pCpnE1 & Wills et al. (1990) \\
\hline
\end{tabular}

*C. trachomatis (mouse pneumonitis).

primers. Sequencing reactions involved incorporation of $\left[{ }^{35} \mathrm{~S}\right] \mathrm{dATP} x \mathrm{~S}$ followed by resolution on $6 \%$ polyacrylamide buffer gradient gels and the sequence was visualized by autoradiography. Using the cloned restriction fragments as templates, the $\mathrm{pCpnE} 1$ and the $\mathrm{pMoPn}$ nucleotide sequences were determined on $6 \%$ polyacrylamide gels using a model $373 \mathrm{~A}$ automated DNA sequencer (Applied Biosystems) with fluorescently labelled dideoxynucleotide terminators. Standard Taq cycle sequencing was performed on double-stranded DNA purified from recombinant clones. For each plasmid the complete nucleotide sequence of both strands was determined and the sequence data assembled and analysed using PCGENE and DNASTAR software.

\section{RESULTS AND DISCUSSION}

\section{Molecular cloning and sequencing of the chlamydial plasmids}

Plasmids are widely distributed throughout the genus Chlamydia and have been successfully cloned and characterized from a broad range of isolates (Girjes et al., 1988; Hugall et al., 1989; Joseph et al., 1986; Kahane \& Sarov, 1986; McClenaghan et al., 1988; Lusher et al., 1989; Palmer \& Falkow, 1986; Timms et al., 1988). However, complete nucleotide sequences have only been determined for plasmids from human C. trachomatis biovars, limiting direct comparison between plasmids from different chlamydial species to restriction enzyme profiling and Southern blot analysis. Therefore the cloning and sequencing of three novel and potentially divergent plasmids will help to define the degree of natural variation between plasmids and to identify important regulatory and replication elements.

The plasmid from C. trachomatis mouse pneumonitis biovar ( $\mathrm{pMoPn}$ ) was cloned as three EcoRI fragments $(3.7,2.0$ and $1.8 \mathrm{~kb})$ into the bacteriophage vector lambda Ziplox. DNA preparations of pCpA1 and pCpnE1 were purified and cloned directly into a plasmid vector (pUC) as EcoRI fragments and additionally as a 'full-length' $\sim 7.5 \mathrm{~kb}$ BalI fragment. A set of unidirectional nested deletions were also constructed using an Erase-a-Base system (Promega) to determine the sequence of one strand of the largest $4.2 \mathrm{~kb} \mathrm{EcoRI}$ fragment of pCpnE1. Synthetic oligonucleotide primers were used to fill in gaps remaining in the sequence and to confirm the sequence spanning the cloning junctions by sequencing from full-length plasmid DNA template. As pMoPn was not available as a full-length clone for this purpose, the sequence of each cloning junction was determined directly from PCR products amplified from native plasmid template spanning each junction.

Analysis showed the plasmid sequences varied in size from $7362 \mathrm{bp}$ (pCpnE1) to $7553 \mathrm{bp}$ (pCpA1). Contrary to a previous report (Palmer \& Falkow, 1986), we found the $7502 \mathrm{bp}$ MoPn plasmid is very similar in length to the highly conserved human C. trachomatis plasmids. With the exception of several incomplete recombinant C. psittaci avian plasmid clones, all chlamydial plasmids characterized by restriction profiling are also around $7.5 \mathrm{~kb}$ (Girjes et al., 1988; Hugall et al., 1989; Joseph et al., 1986; McClenaghan et al., 1988; Lusher et al., 1989; Palmer \& Falkow, 1986; Timms et al., 1988). This remarkable size conservation suggests there may be some physical constraint on plasmid size.

\section{Plasmid organization and putative function}

It was not possible to identify a unique restriction site that is conserved in all plasmids for numbering the sequences (Lusher et al., 1989), however the $22 \mathrm{bp}$ tandem repeats are the most highly conserved region common to all chlamydial plasmids. Therefore the three plasmid sequences determined in this study, as well as the revised pLGV/440 sequence (Thomas \& Clarke, 1992), are numbered from the start of these tandem repeats. The computer-generated ORFs are numbered so that ORF 1 follows directly after the origin of replication.

The genomic organization of each plasmid is strikingly conserved, with eight major ORFs identified greater than 100 amino acids and short non-coding regions between some but not all ORFs (Fig. 1). Both strands of the plasmid contain coding sequences and in every case ORF 2 is located on the complementary strand. Differences in the previously published genetic maps of some human C. trachomatis plasmids may be explained by minor errors in sequencing that alter the apparent initiation or termination codon of the predicted ORFs (Thomas \& Clarke, 1992). The computer-predicted initiation codon for each ORF is also conserved between plasmids: ATG for ORFs 1, 3, 4, 5 and 6, and GTG for ORFs $7 / 8$. There is no consensus ATG codon between the plasmid sequences for ORFs $7 / 8$, however the position of GTG as potential translation initiation codon is conserved and under some circumstances tRNA $^{\text {f-met }}$ will bind and initiate synthesis at GUG as well as AUG codons on bacterial mRNA. Until N- 


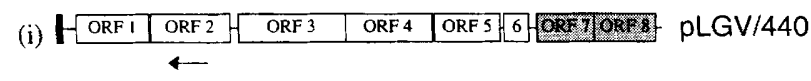

(ii)

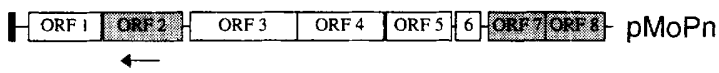

(iii)

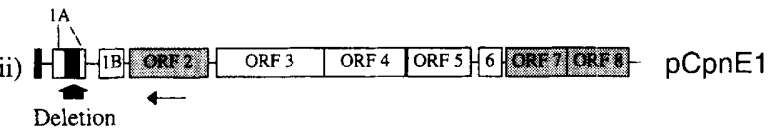

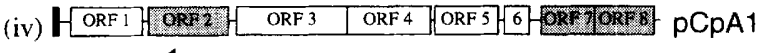

Fig. 1. Alignment of chlamydial plasmid genome maps showing pLGV/440, pMoPn, pCpnE1 and pCpA1. For ease of comparison the maps have been linearized and start with the direct repeats (black box) at nucleotide number 1. Only the eight major ORFs are shown, with the ORF number indicated in each box. The boxes representing ORFs starting with a GTG initiation codon are shaded. All ORFs are transcribed from the same strand, except ORF 2, where the direction of transcription is indicated by an arrow.

Table 2. Translation products of chlamydial plasmid ORFs

\begin{tabular}{|lcccc|}
\hline ORF no. & \multicolumn{4}{c|}{ No. of amino acids } \\
\cline { 2 - 5 } & pLGV440 & pMoPn & pCpnE1 & pCpA1 \\
\hline 1 & 305 & 305 & $83(\mathrm{~A}), 102(\mathrm{~B})^{*}$ & 307 \\
2 & 332 & 330 & 334 & 335 \\
3 & 451 & 451 & 456 & 458 \\
4 & 354 & 353 & 345 & 347 \\
5 & 264 & 264 & 267 & 264 \\
6 & 102 & 102 & 101 & 102 \\
7 & 243 & 254 & 261 & 223 \\
8 & 247 & 246 & 256 & 246 \\
\hline
\end{tabular}

"A and $B$ refer to ORFs $1 \mathrm{~A}$ and $1 \mathrm{~B}$, respectively, in pCpnE1.

terminal sequences are obtained for the polypeptide products of the computer-predicted ORFs the actual initiation codons will remain unknown. The initiation codon for ORF 2 is ATG for all human C. trachomatis plasmids; by sequence comparison we have predicted GTG as the initiation codon for ORF2 from pMoPn, pCpA1 and pCpnE1. Although earlier computer-predicted translation initiation sites within the same reading frame were possible for the pCpnE1 ORF 2 and ORFs 1 , 4 and 6 of pCpA1, these were excluded from our predictions on the grounds of sequence alignment with the corresponding ORF from other chlamydial plasmids and the lack of a clearly distinguishable ribosomebinding site.

The sizes of the chlamydial plasmid ORFs are summarized and compared in Table 2 . The most striking

feature apparent from sequence comparisons is variation in the length of ORF 1 . In the human L2 plasmid sequence, ORF 1 terminates after 260 amino acids (Comanducci et al., 1988), while this ORF is between 305 and 307 amino acids for the avian and all other $C$. trachomatis plasmids. The truncation of ORF 1 in serovar L2 is caused by a single nucleotide deletion which makes a reading frame shift. ORF 1 in the equine plasmid is significantly different and is divided into two smaller ORFs (designated ORFs 1A and 1B) around 200 nucleotides apart (Fig. 2). ORF 1B displays continuous homology with the last 100 amino acids of the fulllength ORF 1 sequence. However, when aligned with the pCpA1 ORF 1 sequence, ORF $1 \mathrm{~A}$ is split into two homologous regions separated by a gap of around 150 nucleotides. This gap represents a deletion that accounts for the reduced size of the equine plasmid compared to other chlamydial plasmids. To guard against the possibility that this deletion in ORF 1 of pCpnE1 was an artefact of cloning, its presence in the native plasmid was confirmed by PCR. C. pneumoniae N16 EB was used as template with a primer pair that straddles the deletion. The PCR product generated from the native pCpnE1 was the same size as that from the cloned pCpnE1 (data not shown). The PCR products from native $\mathrm{pCpnE} 1$ were sequenced confirming the deletion and two stop codons identified in cloned pCpnE1 ORF1.

All chlamydial plasmids have four 22 bp tandem repeats in the intergenic region between ORFs 8 and 1 . In plasmids from other bacterial species, tandem repeats or iterons are involved in plasmid replication, control of copy number and incompatibility (Novick, 1987). The tandem repeats have now been sequenced from several different chlamydial plasmids and the importance of this region for plasmid maintenance is reflected in the degree of sequence conservation between all chlamydial plasmids. Generally the region upstream of the tandem repeats is more AT-rich than the remainder of the plasmid and this region of the C. trachomatis human and MoPn plasmid contains a cluster of AT repeats. The avian and equine plasmids also have markedly AT-rich regions but these are not present as AT repeats. All C. psittaci plasmids have identical repeat sequences including those from avian (Hugall et al., 1989; this study), feline (Lusher et al., 1991) and guinea-pig inclusion conjunctivitis (GPIC) (Lusher et al., 1991) isolates. This $22 \mathrm{bp}$ sequence is conserved in the equine C. pneumoniae plasmid and in the plasmid from the koala urogenital strain. The repeats are also identical to those from the plasmid of the sporadic bovine encephalomyelitis isolate of Chlamydia which is the type strain of C. pecorum (Hugall et al., 1989). Among human C. trachomatis plasmids, the repeats are identical but show two nucleotide substitutions from the conserved C. psittaci repeat sequence, with the $\mathrm{MoPn}$ plasmid differing by a further novel base substitution (Fig. 3).

The functions of some putative plasmid ORFs have been inferred from database searches to identify homology with proteins of known function. The most extensive 


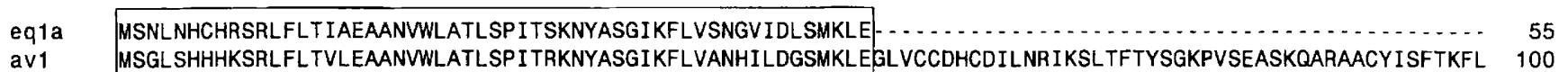

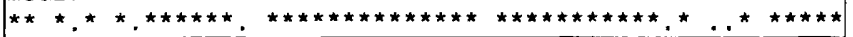

Fig. 2. Alignment of pCpA1 (av1) with pCpnE1 ORFs $1 A$ (eq1a) and $1 B$ (eq1b) using the FASTA package. Identical residues are indicated by an asterisk and similar residues by a dot; gaps in the sequence are shown as dashes. For clarity the sequence of ORF $1 A$ is boxed.

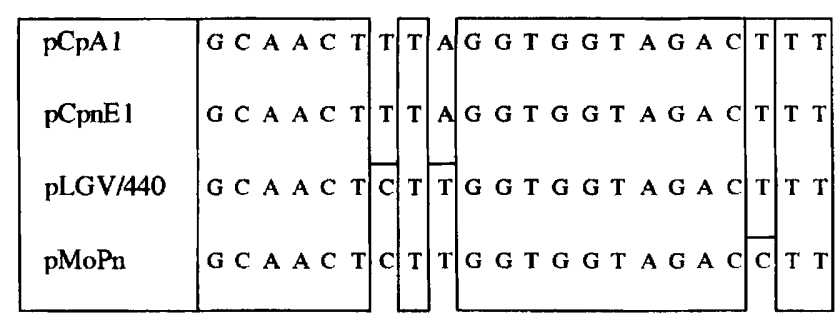

Fig. 3. Alignment of chlamidyial plasmid tandem repeat sequences.

homology observed is between the ORF 3 protein and the DnaB proteins of E. coli and Salmonella typhimurium. The DnaB gene product is a helicase involved in unwinding dsDNA during replication. ORF 2 encodes a protein containing conserved domains belonging to a family of recombinase-like proteins (Buissan \& Roy, 1991). ORF 7 also shares partial homology to several $E$. coli plasmid- and phage-encoded proteins (F, RK2, P1) including SopA and ParA, which are likely to be involved in the regulation of partitioning and copy number of their respective hosts (Motallebi-Veshareh et al., 1990). It is of interest that a number of features common to the SopA/B and ParA/B operons - a tandem arrangement, followed by a direct repeat region and transcription from polycistronic transcripts (Hiraga, 1992) - are also shared by a possible ORF $7 / 8$ operon in chlamydial plasmids (Ricci et al., 1995).

Recombinant ORF 5 has been expressed in vitro and antibodies raised against it can specifically recognize a $28 \mathrm{kDa}$ protein on Western blots of protein from purified chlamydial EBs (Comanducci et al., 1994). This is the only direct evidence for translation of plasmid ORFs in vivo, although plasmid-specific proteins have been observed using in vitro transcription/translation systems or E. coli maxicells and minicells (Clarke \& Hatt,
1986; Joseph et al., 1986; Palmer \& Falkow, 1986). Polypeptide products with apparent molecular masses ranging from 11 to $52 \mathrm{kDa}$ have been identified and generally these sizes are in agreement with the predicted proteins deduced from the plasmid sequences. Several regions of the plasmid are transcriptionally active (Pearce et al., 1991) and Northern blot analysis has demonstrated plasmid-specific transcripts ranging from a few hundred nucleotides to several $\mathrm{kb}$. The transcription of all eight major plasmid ORFs has been studied and temporal regulation, polycistronic transcripts and multiple transcripts for the same ORF appear to be common features (Sriprakash \& Pearce, 1990; Fahr et al., 1992; Comanducci et al., 1993; Ricci et al., 1993, 1995).

ORF 1 has also been implicated in plasmid replication because its size, net positive charge and location downstream of the tandem repeats are characteristic of the origin of replication of a number of $E$. coli plasmids (Filutowicz et al., 1986). The organization of this region is consistent with regulation by iteron-binding systems, in which a plasmid-encoded replication protein binds to one or more sets of tandemly arrayed direct repeats (Novick, 1987). The possible identification of replication forks in this region by electron microscopy (Tam et al., 1992) provides further support that the repeats are involved in the initiation of replication. The ORF 1 and ORF 2 proteins share several amino acid motifs as well as considerable $(32-35 \%)$ amino acid identity, suggesting a functional and possibly an ancestral relationship, although the disruption of ORF 1 in the equine plasmid suggests that ORF 2 could be the major replication protein.

The activity of ORF 2 is likely to be regulated by a complementary base-pairing mechanism involving two short, highly abundant antisense transcripts, characteristic of plasmid replication control by inhibitor targeting systems (Novick, 1987). These transcripts have 


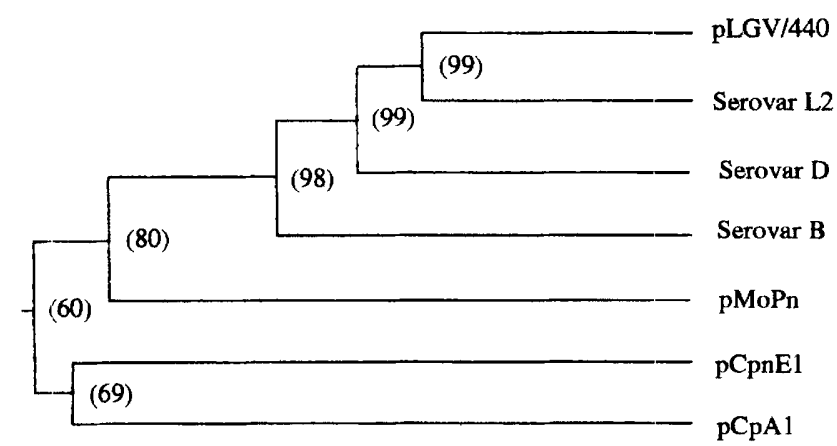

Fig. 4. Dendrogram based on alignment of full-length chlamydial plasmid sequences. The phylogenies are rooted assuming a biological clock, with the sequence conservation (\%) between plasmids shown in parentheses.

now been identified in three C. trachomatis LGV isolates (Fahr et al., 1992; Ricci et al., 1993; Thomas \& Clark, 1994) and in the MoPn biovar (data not shown) and may be a common regulatory element in all chlamydial plasmids.

\section{Phylogenetic analysis}

Several different chlamydial plasmid 'types' have been identified by restriction mapping (Lusher et al., 1989), and computer-derived restriction maps from each of the plasmid sequences determined in this study were all significantly different from each other (data not shown). However, alignments using the Jotun-Hind program (Hein, 1990) demonstrated that with at least $60 \%$ interspecies DNA sequence identity, chlamydial plasmids are more closely related than the corresponding chromosomal DNA. The MoPn and L1 plasmid sequences $(80 \%$ identity) and the pCpA1 and pCpnE1 sequences (69\% identity) are more closely related to each other than the avian C. psittaci and the C. trachomatis L1 plasmids $(60 \%$ identity). This explains why extensive cross-hybridization between C. psittaci and the C. trachomatis plasmids has only been observed under conditions of low stringency (Joseph et al., 1986; Hugall et al., 1989).

A phylogenetic tree based on an alignment of all available full-length plasmid sequences suggests that the $\mathrm{MoPn}$ plasmid is more closely related to human C. trachomatis plasmids than to those of other chlamydial species, while equine and avian plasmids are more closely related to each other (Fig. 4). These findings are consistent with other phylogenetic studies based on total genomic DNA and major outer-membrane protein sequences (Carter et al., 1991; Fitch et al., 1993; Kaltenboeck et al., 1993).

Determination of three novel chlamydial plasmid sequences has revealed extensive sequence conservation between them suggesting that the plasmids have arisen by evolution from a common ancestor. The similarity in size and genomic organization strongly suggests that the mechanisms for plasmid maintenance and general properties are shared. Although sequence analysis did not identify an overall plasmid function, and the existence of plasmid-free strains shows that it is not essential for chlamydial growth, the plasmid could influence the growth or virulence characteristics of its host strain (Comanducci et al., 1994), as bacterial pathogenicity factors are often encoded by plasmids (Eberhard, 1989).

The plasmid genomic organization and the presence of tandem repeats and countertranscripts provide evidence for involvement of both iteron-binding and inhibitor targeting mechanisms in the regulation of plasmid replication. Possibly a combination of both mechanisms could be involved, which has been previously observed for the E. coli plasmid R6K (Patel \& Bastia, 1987).

Molecular research into this important intracellular pathogen has been severely hindered by the lack of a suitable gene transfer system. Recently, transformation of chlamydial EBs has been described (Tam et al., 1994) and the cryptic plasmid is the ideal vector to exploit this advance. To date, the highly conserved and compact nature of the plasmid genome, with little non-coding sequence, has precluded the identification of a suitable cloning site for rational vector development. Comparative plasmid sequence studies have now proven useful in identifying a potential region for the insertion of foreign DNA. Future studies will concentrate on the development of the equine plasmid as a vector for the transformation of chlamydiae.

\section{ACKNOWLEDGEMENTS}

We are very grateful to Sylvia Everson for assistance in the growth and purification of chlamydial EBs and to Janet Gregory for technical support and assistance with sequencing. N.S.T. was supported by an MRC research studentship. This work was supported by grant number 047038 from the Wellcome Trust.

\section{REFERENCES}

An, Q., Radcliffe, G., Vassallo, R., Buxton, D., O’Brien, W. J., Pelletier, D. A., Weisburg, W. G., Klinger, J. D. \& Olive, D. M. (1992). Infection with a plasmid-free variant Chlamydia related to Chlamydia trachomatis identified by using multiple assays for nucleic acid detection. J Clin Microbiol 30, 2814-2821.

Birkelund, S. \& Stephens, R. S. (1992). Construction of physical and genetic maps of Chlamydia trachomatis serovar L2 by pulsed-field gel electrophoresis. J Bacteriol 174, 2742-2747.

Birnboim, H. C. \& Doly, J. (1979). A rapid alkaline extraction procedure for screening recombinant plasmid DNA. Nucleic Acids Res 7, 1513-1523.

Black, C. M., Barnes, R. C., Birkness, K. A., Holloway, B. P. \& Mayer, L. W. (1989). Nucleotide sequence of the common plasmid of Chlamydia trachomatis L2: use of compatible deletions to generate overlapping fragments. Curr Microbiol 19, 67-74.

Black, C. M., Petersson, B., Messmer, T. O., Storey, C., Uhlen, M. \& Olsvik, O. (1994). Identification of three types of $16 \mathrm{~S}$ rDNA genes in Chlamydia pneumoniae strains of human and nonhuman origin. In Chlamydial Infections, Proceedings of the 8th International Symposium on Human Chlamydial Infections, pp. 
193-196. Edited by J. Orfila and others. Bologna: Societa Editrice Esculapo.

Buissan, J. P. \& Roy, P. H. (1991). The $7.5 \mathrm{~kb}$ plasmid of Chlamydia trachomatis codes for a site-specific recombinase. In Abstracts of the 31st Interscience Conference on Antimicrobial Agents and Chemotherapy, abstract 81, p. 112. Washington, DC: American Society for Microbiology.

Campbell, L. A., Kuo, C.-C. \& Grayston, J. T. (1987). Characterization of the new Chlamydia agent, TWAR, as a unique organism by restriction endonuclease analysis and DNA-DNA hybridization. J Clin Microbiol 25, 1911-1916.

Carter, M. W., Al-Mahdawi, S. A. H., Giles, I. G., Treharne, J. D., Ward, M. E. \& Clarke, I. N. (1991). Nucleotide sequence and taxonomic value of the outer membrane protein gene of Chlamydia pneumoniae IOL-207. J Gen Microbiol 137, 465-475.

Clarke, I. N. \& Hatt, C. (1986). In vitro transcription/translation analysis of cloned plasmid DNA from Chlamydia trachomatis serovar L1. In Chlamydial Infections, Proceedings of the 6th International Symposium on Human Chlamydial Infections, pp. 85-88. Edited by D. Oriel, G. Ridgeway, D. Taylor-Robinson \& M. E. Ward. Cambridge: Cambridge University Press.

Comanducci, M., Ricci, S. \& Ratti, G. (1988). The structure of a plasmid of Chlamydia trachomatis believed to be required for growth within mammalian cells. Mol Microbiol 2, 531-538.

Comanducci, M., Ricci, S., Cevenini, R. \& Ratti, G. (1990). Diversity of the Chlamydia trachomatis common plasmid in biovars with different pathogenicity. Plasmid 23, 149-154.

Comanducci, M., Cevenini, R., Moroni, A., Giuliani, M. M., Ricci, S., Scarlato, V. \& Ratti, G. (1993). Expression of a plasmid gene of Chlamydia trachomatis encoding a novel $28 \mathrm{kDa}$ antigen. J Gen Microbiol 139, 1083-1092.

Comanducci, M., Manetti, R., Bini, L., Santucci, A., Pallini, V., Cevenini, R., Suer, J.-M., Orfila, J. \& Ratti, G. (1994). Humoral response to plasmid protein pgp3 in patients with Chlamydia trachomatis infection. Infect Immun 62, 5491-5497.

D’Alessio, J. M., Bebee, R., Hartley, J. L., Noon, M. C. \& Polayes, D. (1992). Lambda Ziplox: automatic subcloning of cDNA. Focus 14, 76-79.

Eberhard, W. G. (1989). Why do bacterial plasmids carry some genes and not others? Plasmid 21, 167-174.

Fahr, M. J., Sriprakash, K. S. \& Hatch, T. P. (1992). Convergent and overlapping transcripts of the Chlamydia trachomatis $7.5 \mathrm{~kb}$ plasmid. Plasmid 28, 247-257.

Filutowicz, M., McEachern, M. J. \& Helinski, D. R. (1986). Positive and negative roles of an initiator protein at an origin of replication. Proc Natl Acad Sci USA 83, 9645-9649.

Fitch, W. M., Peterson, E. M. \& de la Maza, L. M. (1993). Phylogenetic analysis of the outer-membrane protein genes of chlamydiae, and its implication for vaccine development. Mol Biol Evol 10, 892-913.

Fukushi, H. \& Hirai, K. (1992). Proposal of Chlamydia pecorum sp. nov. for Chlamydia strains derived from ruminants. Int I Syst Bacteriol 42, 306-308.

Girjes, A. A., Hugall, A. F., Timms, P. \& Lavin, M. F. (1988). Two distinct forms of Chlamydia psittaci associated with disease and infertility in Phascolarctos cinereus (Koala). Infect Immun 56, $1897-1900$.

Hatch, T. P. (1988). The metabolism of Chlamydia. In Microbiology of Chlamydia, pp. 98-110. Edited by Alman L. Barron. Boca Raton, FL: CRC Press.
Hatt, C., Ward, M. E. \& Clarke, I. N. (1988). Analysis of the entire sequence of the cryptic plasmid of Chlamydia trachomatis serovar L1. Evidence for involvement in DNA replication. Nucleic Acids Res 16, 4053-4067.

Hattori, M. \& Sakaki, Y. (1986). Dideoxy sequencing method using denatured plasmid templates. Anal Biochem 152, 232-238.

Hein, J. J. (1990). Unified approach to alignment and phylogenies. Methods Enzymol 183, 626-645.

Hiraga, S. (1992). Chromosome and plasmid partition in Escherichia coli. Annu Rev Biochem 61, 283-306.

Hugall, A., Timms, P., Girjes, A. A. \& Lavin, M. F. (1989). Conserved DNA sequences in chlamydial plasmids. Plasmid 22, 91-98.

Joseph, T., Nano, F. E., Garon, C. F. \& Caldwell, H. D. (1986). Molecular characterization of Chlamydia trachomatis and Chlamydia psittaci plasmids. Infect Immun 51, 699-703.

Kahane, A. \& Sarov, I. (1986). Cloning of a chlamydial plasmid: its use as a probe and in vitro analysis of encoded polypeptides. Curr Microbiol 14, 255-258.

Kaltenboeck, B., Kousoulas, K. \& Storz, J. (1993). Structures of and allelic diversity and relationships among the major outer membrane protein (ompA) genes of the four chlamydial species. $J$ Bacteriol 175, 487-502.

Kingsbury, D. T. \& Weiss, E. (1968). Lack of deoxyribonucleic acid homology between species of the genus Chlamydia.J Bacteriol 96, 1421-1423.

Lovett, M., Kuo, K.-K., Holmes, K. \& Falkow, S. (1980). Plasmids of the genus Chlamydia. In Current Chemotherapy and Infectious Diseases, vol. 2, pp. 1250-1252. Edited by J. Nelson \& C. Grassi. Washington, DC: American Society for Microbiology.

Lusher, M., Storey, C. C. \& Richmond, S. J. (1989). Plasmid diversity within the genus Chlamydia. J Gen Microbiol 135, 1145-1151.

Lusher, M., Storey, C. C. \& Richmond, S. J. (1991). Extrachromosomal elements of the genus Chlamydia. Adv Gene Technol 2, 261-285.

McClenaghan, M., Honeycombe, J. R., Bevan, B. J. \& Herring, A. J. (1988). Distribution of plasmid sequences in avian and mammalian strains of Chlamydia psittaci. J Gen Microbiol 134, 559-565.

Motallebi-Veshareh, M., Rouch, D. A. \& Thomas, C. M. (1990). A family of ATPases involved in active partitioning of diverse bacterial plasmids. Mol Microbiol 4, 1455-1463.

Nigg, C. (1942). An unidentified virus which causes pneumonia and systemic infection in mice. Science 95, 49-50.

Novick, R. P. (1987). Plasmid incompatibility. Microbiol Rev 51, 381-395.

Palmer, L. \& Falkow, S. (1986). A common plasmid of Chlamydia trachomatis. Plasmid 16, 52-62.

Patel, I. \& Bastia, D. (1987). A replication initiator protein enhances the rate of hybrid formation between a silencer RNA and an activator RNA. Cell 51, 455-462.

Pearce, B. J., Fahr, M. J., Hatch, H. P. \& Sriprakash, K. S. (1991). A chlamydial plasmid is differentially transcribed during the life cycle of Chlamydia trachomatis. Plasmid 26, 116-122.

Peterson, E. M., Markoff, B. A., Schachter, J. \& de la Maza, L. M. (1990). The $7.5 \mathrm{~kb}$ plasmid present in Chlamydia trachomatis is not essential for the growth of this micro-organism. Plasmid 23, 144-148.

Ricci, S., Cevenini, R., Cosco, E., Comanducci, M., Ratti, G. \& Scarlato, V. (1993). Transcriptional analysis of the Chlamydia 
trachomatis plasmid pCT identifies temporally regulated transcripts, anti-sense RNA and sigma70-selected promoters. Mol Gen Genet 237, 318-326.

Ricci, S., Ratti, G. \& Scarlato, V. (1995). Transcriptional regulation in the Chlamydial trachomatis pCT plasmid. Gene 154, 93-98.

Richmond, S. J., Stirling, P. \& Ashley, C. R. (1982). Virus infecting the reticulate bodies of an avian strain of Chlamydia psittaci. FEMS Microbiol Lett 14, 31-36.

Sambrook, J., Fritsch, E. F. \& Maniatis, T. (1989). Molecular Cloning: a Laboratory Manual, 2nd edn. Cold Spring Harbor, NY: Cold Spring Harbor Laboratory.

Sanger, F., Nicklen, S. \& Coulson, A. R. (1977). DNA sequencing with chain-terminating inhibitors. Proc Natl Acad Sci USA 74, 5463-5467.

Schachter, J. \& Meyer, K. F. (1969). Lymphogranuloma venereum II. Characterisation of some recently isolated strains. J Bacteriol 99, 636-638.

Sriprakash, K. S. \& MacAvoy, E. S. (1987). Characterization and sequence of a plasmid from the trachoma biovar of Chlamydia trachomatis. Plasmid 18, 205-214.

Sriprakash, K. S. \& Pearce, B. J. (1990). Mapping of transcripts encoded by the plasmid in Chlamydia trachomatis. FEMS Microbiol Lett 71, 299-304.

Storey, C. C., Lusher, M. \& Richmond, S. J. (1989). Analysis of the complete nucleotide sequence of Chp1, a phage from an avian strain of Chlamydia psittaci. J Gen Virol 70, 3381-3390.

Storey, C. C., Lusher, M., Yates, P. \& Richmond, S. J. (1993).

Evidence for Chlamydia pneumoniae of non-human origin. J Gen Microbiol 139, 2621-2626.

Tam, J. E., Davis, C. H., Thresher, R. J. \& Wyrick, P. B. (1992).
Location of the origin of replication for the $7.5 \mathrm{~kb}$ Chlamydia trachomatis plasmid. Plasmid 27, 231-236.

Tam, J. E., Davis, C. H. \& Wyrick, P. B. (1994). Expression of recombinant DNA introduced into Chlamydia trachomatis by electroporation. Can J Microbiol 40, 583-591.

Thomas, N. S. \& Clarke, I. N. (1992). Revised map of the Chlamydia trachomatis (L1/440/LN) plasmid. In Proceedings of the 2 nd European Society for Chlamydial Research, p. 42. Edited by P.-A. Mardh, M. la Placa \& M. E. Ward. Bologna: Societa Editrice Esculapo.

Thomas, N. S. \& Clarke, I. N. (1994). Molecular characterization of the plasmid from the Chlamydia trachomatis mouse pneumonitis biovar. In Chlamydial Infections, Proceedings of the $8 \mathrm{th}$ International Symposium on Human Chlamydial Infections, pp. 251-254. Edited by J. Orfila and others. Bologna: Societa Editrice Esculapo.

Timms, P., Eaves, F. W., Hugall, A. F. \& Lavin, M. F. (1988). Plasmids of Chlamydia psittaci: comparison of isolates by Southern hybridization. FEMS Microbiol Lett 51, 119-124.

Ward, M. E. (1988). The chlamydial developmental cycle. In Microbiology of Chlamydia, pp. 71-95. Edited by Alman L. Barron. Boca Raton, FL: CRC Press.

Wills, J. M., Watson, G., Lusher, M., Mair, T. S., Wood, D. \& Richmond, S. J. (1990). Characterization of Chlamydia psittaci isolated from a horse. Vet Microbiol 24, 11-19.

Yanisch-Perron, C., Vieira, J. \& Messing, J. (1985). Improved M13 phage cloning vectors and host strains: nucleotide sequences of the M13mp18 and pUC19 vectors. Gene 33, 103-119.

Received 31 October 1996; revised 24 January 1997; accepted 14 February 1997. 